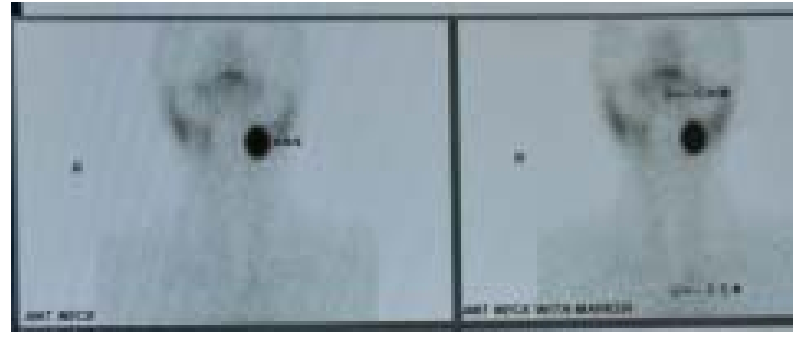

Figure 2.

The occurrence of ectopic thyroid tissue is a relatively rare developmental abnormality which is consequent to aberrant embryogenesis of the primordial thyroid gland during its passage from the floor of the primitive foregut to its final pre-tracheal position [1,2]. Its occurrence is around one per one hundred thousand to three hundred thousand of human population. In clinical practice the most frequent location of ectopic thyroid tissue is at the region of the foramen cecum, accounting for about $90 \%$ of the reported cases [3].

\section{References}

1. Noussios G, Anagnostis P, Goulis DG, et al. Ectopic thyroid tissue: anatomical, clinical, and surgical implications of a rare entity. European Journal of Endocrinology 2011; 165: 375-82.

2. Babazade F, Mortazavi H, Jalalian H, et al. Thyroid tissue as a submandibular mass: a case report. Journal of Oral Science 2009; 51: 655-7.

3. Weber AL, Randolph G, Aksoy FG. The thyroid and parathyroid glands. CT and MR imaging and correlation with pathology and clinical findings. Radiologic Clinics of North America 2000; 38: 1105-29.

\title{
A case of Hymenolepis diminuta (rat tape worm) infestation in a child
}

\author{
V P Sinhabahuํㅜ, T M R Perera ${ }^{1}$, S Samarasinghe $^{2}$
}

Ceylon Medical Journal 2014; 59:70-71

A five-year old boy presented with fever, watery stools and a febrile convulsion on day one of the illness. He has had on and off abdominal pain for 5 months. No urinary symptoms nor blood stained stools noted. He has had a febrile convulsion at 9 months. Growth and development were appropriate for the age. The immunisation was uptodate. Examination was unremarkable. Microscopic examination of faeces showed 10-12 pus cells and 15-16 red cells per high power field and eggs of Hymenolepis diminuta (Figure 1). Stool culture did not yield any significant pathological organism. Stool virology could not be performed. Child was treated with praziquantal $10 \mathrm{mg} / \mathrm{kg}$ as a single dose. A microenema was administered 2 hours later and a 24 hour stool collection was done to check the excretion of the worms which yielded numerous worm segments (Figure 2). A repeat stool examination was done one month later which did not show evidence of $H$. diminuta infestation.

The natural reservoir and definitive host of H.diminuta are rodents. Coprophilic arthropods such as flea and beetle species act as intermediate hosts [1]. Humans act as definitive hosts only when they ingest cysticercoid larvae infected arthropods with food and fomites. This is the reason why $H$. diminuta infestation is uncommon in humans [1]. Only a limited number of cases have been reported globally [1]. H. diminuta is known to cause abdominal pain and loose stools in children [3]. $H$. diminuta infestation has not been reported to cause seizures before. Praziquantel and niclosamide can be used for treatment of $H$. diminuta infestations.

${ }^{1}$ University Paediatric Unit, Colombo South Teaching Hospital, ${ }^{2}$ Medical Research Institute, Colombo, Sri Lanka. Correspondence: VPS, e-mail: <Sinbad.Ik@gmail.com>. Received 30 November 2013 and revised version accepted 29 March 2014. Competing interests: none declared. 


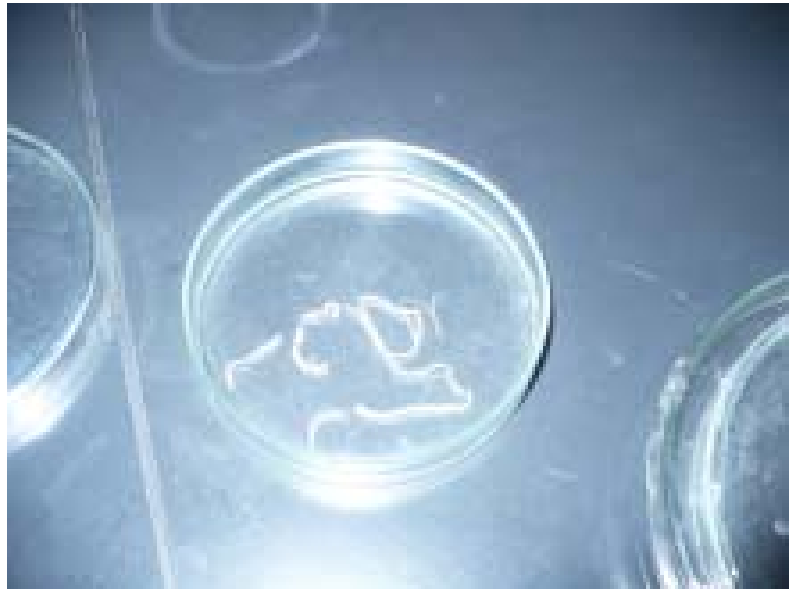

Figure 1.

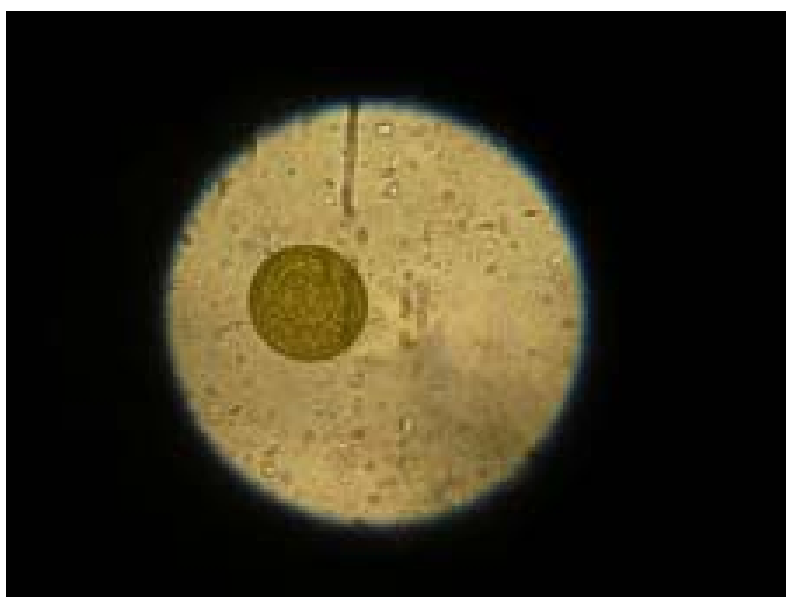

Figure 2.

\section{Acknowledgements}

We acknowledge the laboratory work done by Mrs. Thushara Siriwardena, Department of Parasitology, Medical Research Institute, Colombo.

\section{References}

1. Patamia I, Cappello E, Greco F, et al. A Human Case of

Hymenolepis diminuta in a Child from Eastern Sicily. Korean Journal of Parasitology 2010; 48: 167-9.

2. Dissanaike AS, Parasitic zoonoses in Sri Lanka: an update. Ceylon Medical Journal 2002; 47: 46 -7.

3. Thakur NK, Mishra SK, Neupane GP, Jha A. Hymenolepisdiminuta Infection in a Child of 14 month. Journal of Nepal Health Research Council 2009; 7: 49-51. 